\title{
Editorial \\ Dietary Antioxidants and Brain Health: Focus on Cognitive and Affective Disorders
}

\author{
Justyna Godos (D) and Giuseppe Grosso *
}

\author{
Department of Biomedical and Biotechnological Sciences, University of Catania, 95123 Catania, Italy; \\ justyna.godos@gmail.com \\ * Correspondence: giuseppe.grosso@unict.it
}

check for updates

Citation: Godos, J.; Grosso, G. Dietary Antioxidants and Brain Health: Focus on Cognitive and Affective Disorders. Antioxidants 2021, 10, 1659. https://doi.org/10.3390/ antiox10111659

Received: 11 October 2021

Accepted: 20 October 2021

Published: 22 October 2021

Publisher's Note: MDPI stays neutral with regard to jurisdictional claims in published maps and institutional affiliations.

Copyright: (c) 2021 by the authors. Licensee MDPI, Basel, Switzerland. This article is an open access article distributed under the terms and conditions of the Creative Commons Attribution (CC BY) license (https:// creativecommons.org/licenses/by/ $4.0 /)$.
Today's society faces major global challenges, including the continuously increasing prevalence of mental disorders and neurodegenerative diseases, with different risk factors contributing to the trend [1]. As a result, targeting modifiable lifestyle habits, including diet, has been recognized as an essential strategy to reduce this burden [2].

Dietary antioxidants, such as polyphenols, which are bioactive compounds characteristically contained in plant-based diets, have been demonstrated to play a role in the prevention of numerous non-communicable diseases, including cardiovascular diseases [3], hypertension [4], diabetes [5] and cancer [6,7]. Interestingly, recent evidence has suggested that dietary polyphenols may also be implicated in brain health through both indirect and direct mechanisms, including, but not limited to, modulation of neuro-and systemic inflammation, adult neurogenesis, cerebrovascular function, as well as gut microbiota [8,9].

This Special Issue focused on providing literature syntheses and new insights into the effects of antioxidant molecules, as well as antioxidant-rich foods and dietary patterns, toward neurodegenerative diseases and mental disorders.

Among the published articles, two intervention studies explored chronic and acute effects of polyphenol-containing extracts on cognitive function $[10,11]$. One cross-sectional analysis investigated the association between dietary phenolic acids and cognitive status in older adults [12]. A randomized, double-blind, placebo-controlled, crossover clinical trial conducted on healthy middle-aged volunteers supplemented with fruit- and vegetablebased extract containing polyphenols reported significant improvements in executive function in terms of short-term memory, working memory, selective and sustained attention, and speed of processing when compared to the placebo group [10]. Similarly, another randomized, double-blind, placebo-controlled, crossover clinical trial conducted among healthy students reported that polyphenols-rich grape and blueberry extracts, implemented in the context of a healthy lifestyle, might be a safe alternative to acutely improved working memory and attention during a sustained cognitive effort [11]. Finally, a study conducted in a cohort of older Italian adults showed an association between the habitual dietary intake of phenolic acids (notably contained in coffee, berries, nuts, artichokes, and olive oil) and cognitive status, demonstrating that individuals with a lower intake of phenolic acids were more likely to have impaired cognition [12].

Several literature reviews aimed to comprehensively summarize the existing evidence on the effects of antioxidants, including polyphenols, toward cognitive and affective disorders, as well as mental health, and provide a mechanistic basis for their actions [13-19]. The findings confirmed the implications of diet and dietary antioxidants in the brain and mental health through various mechanisms, such as the modulation of neuroinflammation, adult neurogenesis, synaptic plasticity [13], as well as mitophagy [14]. Likewise, an overview was provided on the insights into how nutraceuticals may regulate cognitive function by targeting the TGF- $\beta 1$ signaling pathway [15] and oxidative response [16]. In addition, an assessment of the preclinical and clinical studies on the effect of therapies able to reduce oxidative stress and mitochondrial alterations on the cognitive dysfunction associated 
with Down syndrome was published [17]. A review summarizing the effects of Royal jelly (RJ), the main food of queen bees, highlighted that it might promote brain cell survival and function by targeting multiple adversities in the neuronal microenvironment, such as inflammation, oxidative stress, mitochondrial alterations, and bioenergetic challenges [18]. Finally, a possible role of certain herbs, namely Scutellaria baicalensis (S. baicalensis), Hericium erinaceus (H. erinaceus), and Rhodiola rosea ( $R$. rosea), in modulating neurotransmitter and neuroendocrine systems, stimulating neurogenesis and the synthesis of neurotrophic factors was emphasized [19].

The new insights on the effect of dietary antioxidants on brain disorders provided in this Special Issue are encouraging. Nonetheless, further research is needed to confirm and better understand the mental health benefits of dietary antioxidants.

Funding: This research received no external funding.

Conflicts of Interest: The authors declare no conflict of interest.

\section{References}

1. GBD 2019 Diseases and Injuries Collaborators Global Burden of 369 Diseases and Injuries in 204 Countries and Territories, 1990-2019: A Systematic Analysis for the Global Burden of Disease Study 2019. Lancet 2020, 396, 1204-1222. [CrossRef]

2. GBD 2019 Risk Factors Collaborators Global Burden of 87 Risk Factors in 204 Countries and Territories, 1990-2019: A Systematic Analysis for the Global Burden of Disease Study 2019. Lancet 2020, 396, 1223-1249. [CrossRef]

3. Micek, A.; Godos, J.; Del Rio, D.; Galvano, F.; Grosso, G. Dietary Flavonoids and Cardiovascular Disease: A Comprehensive Dose-Response Meta-Analysis. Mol. Nutr. Food Res. 2021, 65, e2001019. [CrossRef]

4. Godos, J.; Vitale, M.; Micek, A.; Ray, S.; Martini, D.; Del Rio, D.; Riccardi, G.; Galvano, F.; Grosso, G. Dietary Polyphenol Intake, Blood Pressure, and Hypertension: A Systematic Review and Meta-Analysis of Observational Studies. Antioxidants $2019,8,152$. [CrossRef] [PubMed]

5. Guo, X.-F.; Ruan, Y.; Li, Z.-H.; Li, D. Flavonoid Subclasses and Type 2 Diabetes Mellitus Risk: A Meta-Analysis of Prospective Cohort Studies. Crit. Rev. Food Sci. Nutr. 2019, 59, 2850-2862. [CrossRef] [PubMed]

6. Grosso, G.; Godos, J.; Lamuela-Raventos, R.; Ray, S.; Micek, A.; Pajak, A.; Sciacca, S.; D’Orazio, N.; Del Rio, D.; Galvano, F. A Comprehensive Meta-Analysis on Dietary Flavonoid and Lignan Intake and Cancer Risk: Level of Evidence and Limitations. Mol. Nutr. Food Res. 2017, 61, 1600930. [CrossRef] [PubMed]

7. Micek, A.; Godos, J.; Brzostek, T.; Gniadek, A.; Favari, C.; Mena, P.; Libra, M.; Del Rio, D.; Galvano, F.; Grosso, G. Dietary Phytoestrogens and Biomarkers of Their Intake in Relation to Cancer Survival and Recurrence: A Comprehensive Systematic Review with Meta-Analysis. Nutr. Rev. 2021, 79, 42-65. [CrossRef] [PubMed]

8. Caruso, G.; Torrisi, S.A.; Mogavero, M.P.; Currenti, W.; Castellano, S.; Godos, J.; Ferri, R.; Galvano, F.; Leggio, G.M.; Grosso, G.; et al. Polyphenols and Neuroprotection: Therapeutic Implications for Cognitive Decline. Pharmacol. Ther. 2021, 108013, in press. [CrossRef] [PubMed]

9. Grosso, G. Nutrition and Aging: Is There a Link to Cognitive Health? Int. J. Food Sci. Nutr. 2020, 71, 265-266. [CrossRef] [PubMed]

10. Carrillo, J.Á.; Arcusa, R.; Zafrilla, M.P.; Marhuenda, J. Effects of Fruit and Vegetable-Based Nutraceutical on Cognitive Function in a Healthy Population: Placebo-Controlled, Double-Blind, and Randomized Clinical Trial. Antioxidants 2021, $10,116$. [CrossRef] [PubMed]

11. Philip, P.; Sagaspe, P.; Taillard, J.; Mandon, C.; Constans, J.; Pourtau, L.; Pouchieu, C.; Angelino, D.; Mena, P.; Martini, D.; et al. Acute Intake of a Grape and Blueberry Polyphenol-Rich Extract Ameliorates Cognitive Performance in Healthy Young Adults During a Sustained Cognitive Effort. Antioxidants 2019, 8, 650. [CrossRef] [PubMed]

12. Godos, J.; Caraci, F.; Micek, A.; Castellano, S.; D’Amico, E.; Paladino, N.; Ferri, R.; Galvano, F.; Grosso, G. Dietary Phenolic Acids and Their Major Food Sources Are Associated with Cognitive Status in Older Italian Adults. Antioxidants 2021, 10, 700. [CrossRef] [PubMed]

13. Godos, J.; Currenti, W.; Angelino, D.; Mena, P.; Castellano, S.; Caraci, F.; Galvano, F.; Del Rio, D.; Ferri, R.; Grosso, G. Diet and Mental Health: Review of the Recent Updates on Molecular Mechanisms. Antioxidants 2020, 9, 346. [CrossRef] [PubMed]

14. Varghese, N.; Werner, S.; Grimm, A.; Eckert, A. Dietary Mitophagy Enhancer: A Strategy for Healthy Brain Aging? Antioxidants 2020, 9, 932. [CrossRef] [PubMed]

15. Grasso, M.; Caruso, G.; Godos, J.; Bonaccorso, A.; Carbone, C.; Castellano, S.; Currenti, W.; Grosso, G.; Musumeci, T.; Caraci, F. Improving Cognition with Nutraceuticals Targeting TGF-B1 Signaling. Antioxidants 2021, $10,1075$. [CrossRef] [PubMed]

16. Ramli, N.Z.; Yahaya, M.F.; Tooyama, I.; Damanhuri, H.A. A Mechanistic Evaluation of Antioxidant Nutraceuticals on Their Potential against Age-Associated Neurodegenerative Diseases. Antioxidants 2020, 9, 1019. [CrossRef] [PubMed]

17. Rueda Revilla, N.; Martínez-Cué, C. Antioxidants in down Syndrome: From Preclinical Studies to Clinical Trials. Antioxidants 2020, 9, 692. [CrossRef] [PubMed] 
18. Ali, A.M.; Kunugi, H. Royal Jelly as an Intelligent Anti-Aging Agent-A Focus on Cognitive Aging and Alzheimer's Disease: A Review. Antioxidants 2020, 9, 937. [CrossRef] [PubMed]

19. Limanaqi, F.; Biagioni, F.; Busceti, C.L.; Polzella, M.; Fabrizi, C.; Fornai, F. Potential Antidepressant Effects of Scutellaria Baicalensis, Hericium Erinaceus and Rhodiola Rosea. Antioxidants 2020, 9, 234. [CrossRef] [PubMed] 